\title{
HIV/AIDS risk factors and economic empowerment needs of female sex workers in Enugu Urban, Nigeria
}

\author{
N.G. ONYENEHO \\ Department of Sociology/Anthropology, University of Nigeria, Nsukka, Enugu State, Nigeria \\ nkechux@yahoo.com
}

\begin{abstract}
While successes are recorded in the developed world with respect to control of HIV/ AIDS, the dream of halting and reversing its spread seems to be a mirage in most parts of the developing world. The forces that drive the transmission of HIV / AIDS in Nigeria, as in many other resource poor societies include the activities of high-risk groups. Commercial sex workers remain a major source of HIV / AIDS transmission in Nigeria. The knowledge, attitude and practice (KAP) of HIV / AIDS among female sex workers (FSWs) faced with the threat of contracting HIV / AIDS were assessed. A total of $135 \mathrm{FSWs}$ from four most popular brothels in Enugu were interviewed with a structured interview schedule. Six focus group discussion (FGD) sessions were held with FSWs from neighbouring communities. FSWs in Enugu were of diverse socioeconomic backgrounds. They were however mostly in their productive ages of 16-47, with a mean age of 26.9 years. Poverty was the common reason for sex work. Some engaged in sex work to provide their school needs and those of other dependants. The respondents were aware of HIV / AIDS and dread being infected by it because of the stigma and absence of cure. Three percent do not use condom at all. Others use unorthodox methods (e.g. douching with salt solution immediately after sex), if a client refuses to use condom. Condom use depended on the client's choice. Misconceptions exist among the respondents on mode of transmission. Perceptual factors, more than demographic differences played great role in the attitude of the FSWs towards HIV/AIDS. Steps need to be taken to improve on the level of knowledge of HIV / AIDS among the respondents. This should cut across socio-demographic lines and should target the perceptual factors, which tended to provide adequate explanation for the attitude of the respondents to HIV / AIDS. The FSWs should be provided with income earning skills to improve their income earner ability and make them self-reliant.
\end{abstract}

Key words: HIV / AIDS, risk factor, female, sex workers, Nigeria

\section{Introduction}

As the control of the human immunodeficiency virus (HIV) assume position of centrality in social development discourse among policy makers, scientists and practitioners, worldwide and sub Saharan Africa in particular, the factors that drive its transmission come into focus. The HIV, with its resultant acquired immune deficiency syndrome (AIDS) is by far the most challenging phenomenon confronting public health specialists today. In spite of efforts to curtail its spread in societies, it remains the greatest killer of man, poses ahead of such other killer diseases like malaria and tuberculosis (Erah et al., 2003). The worldwide epidemic disproportionately affect Sub-Saharan Africa where two thirds of HIV infected people live (Onwuliri \& Joloyemi, 2007). With just over 10\% of the world's population, Sub-Saharan Africa is home to $64 \%$ of HIV positive people and $90 \%$ of children ( $<15$ years) living with the virus. Twelve million Sub-Saharan African children are orphans due to AIDS and around 59\% (13.3 million) cases of the HIV positive adults in the region are women (UN, 2006).

Although, prevention efforts are proving successful in other regions, deaths due to HIV/ AIDS and new infections continue to increase in others, threatening to rubbish the millennium development goals (MDG) targets of halting HIV by 2015 and reversing its spread (UN, 2006). Nigeria is one of such countries where the efforts to mitigate the spread of the virus seems futile, as AIDS related deaths are on a steady rise. According to World Heath Report (WHR, 2006), HIV prevalence in Nigeria in 2003 was $5.4 \%$. Deaths due to HIV in the same year were $246 / 100,000$ people. The death and DALY estimate by cause show that HIV contributed to $5.0 \%$ of the deaths in 2000 . Ten years earlier deaths due to HIV were less than $1 \%$. It rose to $7 \%$ and $8 \%$ in 2001 and 2005 respectively (UN, 2006). These statistics are indicative of the rampage the virus is causing in Nigeria.

A number of factors, including sexual behaviours and poor knowledge of the virus as well as inadequate protection among high- 
risk populations, like the female sex workers (FSWs) are surmised to be the driving engine of HIV transmission in Nigeria. Unprotected commercial sex has been identified with a significant role in many HIV epidemics (Overs, 2002). The illegal status or lack of clarity in the legal status of sex work encourages clandestine practices and operation in hideouts in many societies including Nigeria. The constitution of the Federal Republic of Nigeria is silent on sex work. As a result, sex workers, brothel operators, implementing partners, and even policy makers are uncertain of the legal status of sex work (Onwuliri \& Jolayemi, 2007). Yet, occasionally we have the law enforcement agencies like the Police raid the brothels, arresting and sacking female sex workers from their operational bases. Nigeria is guided by two legal codes. These are the Penal Code, which operates in northern Nigeria, and the Criminal Code, which operates in southern Nigeria. Both codes criminalize sex work and therefore hinder advocacy efforts to promote the rights of sex workers. The recent adoption of the Moslem Sharia law in some northern parts of the country has resulted in sex work going underground and making it more difficult to reach FSWs with interventions or relocating to more conducive environments, especially in the Southern States, Enugu State inclusive.

Surveys have consistently shown a high and rising HIV prevalence among sex workers, presumed major reservoir of HIV infection in the country (USAID, 2002). A behavioural surveillance survey conducted in 2000 reported that knowledge of HIV prevention methods was low among FSWs; their attitudes towards sexuality and reproductive health issues present a source of concern (FHI, 2002).

The low economic status of FSWs heightens their vulnerability as they engage in unprotected sex. They lack powers to negotiate safe sex and condom. At other times they may be raped or coerced into violent sex; dry sex, with its consequent abrasion and bleeding, increases their risk of contracting HIV (Okeibunor, 1999). They are disadvantaged by a lack of self-esteem and adequate negotiation skills, which compromises their ability to manage the situation and to seek legal action (EUROPAP / TAMPEP, 1998; Metzenrath, 1998; Carrington \& Betts, 2001; Lamptey et al., 2002; Onwuliri et al., 2003). In addition, FSWs face constant sexual harassment and abuse from law enforcement agents such as police officers. Worse still the hazy standing of the law in matters status of sex work makes legal protection of sex workers impracticable and HIV interventions for them difficult. The daunting challenges contribute to the vulnerability, risk, and rising trend of infection among FSWs. Yet targeting interventions to FSWs remains an effective way to reduce the spread of HIV.

In view of these factors hindering advocacy efforts on behalf of the rights of FSWs, the only option may be the improvement of the economic status of the FSWs, which studies have identified as the driving force in the sex work among poor women, while improving their knowledge, attitude and practices about HIV/AIDS issues (Overs, 2002). This study was thus designed to explore and describe the current knowledge, attitude and practices on HIV / AIDS issues among FSWs in Enugu as well as their preference for income generating skills. It is envisaged that the results of this study will be useful in the design of HIV / AIDS education and skill acquisition training for FSWs in Enugu State in Nigeria.

\section{Materials and Methods}

\section{Study area and population}

The study focused on the four major brothels, namely, Cypaco, Happy State, Gariki II and One Nigeria in Enugu Town and Uwani, in Enugu State, Nigeria. Enugu town lies between longitude $7^{\circ} 29^{\prime}$ and $7^{0} 33^{\prime} \mathrm{E}$, and latitude $6^{0} 27^{\prime}$ and $6^{0} 29^{\prime} \mathrm{N}$. As a seat of State administration, Enugu Town attracts a lot of people from different walks of life and from different ethnic and religious backgrounds. The 2006 population census put the population at 244,852 persons (NPC, 2007). Enugu Town is divided into layouts, namely Asata, Ogui, Ogbete, and China-Town or New Heaven. The others are Independence layout, G.R.A, Iva Valley Quarters and the Secretariat Quarters. Like Enugu Town, people of different walks of life, from different sociocultural background populate Uwani. Uwani is the headquarters of Enugu South LGA, recently carved out of Enugu North LGA. It lies between longitude $7^{0} 29^{\prime}$ and $7^{0} 33^{\prime} \mathrm{E}$, and latitude $6^{0} 25^{\prime}$ and $6^{0} 27^{\prime} \mathrm{N}$.

Though highly christianized and civilized, the people of Enugu attach great importancetocertainacts considered abominable and sinful against the earth (Okeibunor, 1999). Some of such acts are sexual activities out of wedlock and sex for money. Here, sex works is treated with impunity and sex workers maintain relative invisibility, making them hard to reach with health programmes. 


\section{Study design and sampling procedure}

The study was designed to allow an assessment of the current knowledge, attitude and practices on HIV/AIDS among FSWs in Enugu State and provide baseline data for the design and implementation of HIV/AIDS education programme. The cross-sectional approach was adopted in collecting quantitative data from FSWs in Enugu Town. Qualitative data were collected, prior to the collection of quantitative data because literature shows that sexual behaviour in Africa is socio-culturally determined and can be influenced by multiple factors that are not personal to the individual. These issues were explored in-depth in the qualitative study using focus group discussions (FGD). The FGDs also provided opportunities for structuring the questions in the quantitative study.

All the 135 FSWs, from the four major brothels in Enugu Town and Uwani were enlisted in the study. A total sample was adopted because of the small number of FSWs in the study communities. The number, is however adequate to sustain the study, and generate answers for the research questions

\section{Data collection}

The major instrument for data collection was a uniform set of interview schedule, which sought information on the socio-demographic characteristics of the FSWs. The interview schedule also ensured information on the knowledge, attitude and practice about HIV / AIDS among the FSWs as well as their willingness to participate in peer education programmes. Furthermore, it provided information on the income generating skills the FSWs would like to be trained on. The interview schedule items were structured with inputs from the FGD. The interview schedules were administered by members of the Society for Women and AIDS, Nigeria (SWAAN), a non governmental organization working in the area of reproductive health promotions among vulnerable group, trained on the objectives and methodology. Focus Group Discussions (FGDs) were held with FSWs in neighbouring communities to explore in-depth the issues that drive HIV / AIDS in the State. For this purpose, six groups of FSWs (6-8 in number) were constituted in the brothels outside the study communities to discuss the issues.

\section{Data analysis}

Analysis of the qualitative data placed emphasis on the interpretation, description and recording/ writing of what was actually said. These were ethnographically summarized and built around key issues like knowledge, attitudes and perceptions as well as practices about sexuality and HIV / AIDS among FSWs.

Theinterview schedule data wereentered in the Epi-Info version 6 and analyzed with the SPSS statistical package. Simple descriptive statistics like the means, median, modes and percentages as well as graphic illustrations were employed in the presentation of the main characteristics of the study respondents. Correlation analysis was done using Pearson's $R$ to illustrate the relationship between certain socio-demographic, cognitive and perceptual characteristics of the respondents with their attitudes and practices towards HIV/AIDS issues, among others.

\section{Ethical consideration}

Approval for the study was received from the Enugu State Ministry of Social Welfare. In addition to this the consent of the respondents to be enlisted in the study was obtained prior to the commencement of the data collection process.

\section{Results}

\section{Socio-demographic characteristics of respondents}

Slightly, more than forty percent $(40.7 \%)$ of the 135 respondents came from brothels in the low class, usually filthy area of Enugu town. The classification of respondents and their brothel did not however differ with key demographic factor like education $(P>0.18)$. Abouthalf $(51.1 \%)$ had secondary education. Others $(11.9 \%, 34.8 \%$ and $2.2 \%$ ) had no formal education, primary and post secondary education, respectively. High proportions (83.6\% and $91.3 \%$ ) of those in the low and high-class areas respectively had at least primary level of education.

The age range was from 16 to 47 years with a mean age (SD) of $26.9 \pm 5.5$ years. The mode and median ages were 26 years and 26 years respectively. The age interval 25-29 years provided the highest proportion $(43.8 \%)$ of respondents. The interval 20-24 years followed this with $32.0 \%$ of the respondents coming from that age group. This is a relatively young group, some of whom should be in high school and yet mature to be independently working to earn a living.

About two-thirds (67.9\%) of the respondents indicated that they have seen 
someone with the HIV symptoms (Table 1). For almost a third (31.5\%) of the respondents the person they suspect to be living with HIV/ AIDS is their friend. A similar proportion of those who have seen one with the symptoms of HIV indicated that the suspected person is their colleague (FSW). This definitely points out the level of danger posed by the sex workers to their clients. A majority of the respondents believed the ultimate consequence of infection with HIV is death $(95.4 \%)$. However, $34.4 \%$ were bothered about the rejection one living with HIV/AIDS suffers in society while $22.9 \%$ associate it with eventual poverty. This may have to do also with the rejection in society because "no one will want to have any dealings with one living with HIV/AIDS", argued one of the sex workers in an FGD session. point. This shows the level of poor perception of HIV / AIDS among the respondents.

A majority $(61.2 \%)$ of the respondents does nothing, other than commercial sex work for a living. Some $(15.7 \%)$, however, combine commercial sex work with petty trading while $7.5 \%$ of the respondents were still students. Others $(15.7 \%)$ indicated that they engage in any other businesses that may come their way to support themselves. More than half $(55.6 \%)$ of the respondents were never married. A third $(33.3 \%)$ of the respondents was married before. The other $11.1 \%$ were married and left their homes to earn some money to support the family. Though curious, the FGD with groups of FSWs revealed that this is a common phenomenon in most big cities, and it obtains for different reasons. Participants in all FGD

\section{Table 1: Distribution of respondents by their perceptions of HIV/AIDS infection}

\begin{tabular}{lll}
\hline Perceptions of HIV/AIDS Infection & Frequency & Percentages \\
\hline Ever seen one with HIV symptoms & & \\
Yes & 89 & 67.9 \\
No & 42 & 32.1 \\
Relationship to person with HIV symptoms & 5 & 5.6 \\
A relation & 28 & 31.5 \\
Friend & 13 & 14.6 \\
Colleague & 29 & 32.6 \\
Community member & 6 & 6.7 \\
Neighbour & 8 & 9.0 \\
Sick person in hospital & & \\
Consequences of getting infected with HIV/AIDS & 125 & 95.4 \\
Death & 25 & 19.1 \\
Poor health & 25 & 19.1 \\
Having infected children & 45 & 34.4 \\
Rejection in society & 30 & 22.9 \\
Poverty & 2 & 1.5 \\
Nothing & & \\
How dangerous is infection with HIV/AIDS & 125 & 95.4 \\
Very dangerous & 5 & 3.8 \\
Just like any other disease & 1 & 0.8 \\
Not dangerous & & \\
\hline
\end{tabular}

Almost all (95.4\%) of the respondents see HIV/ AIDS as a very dangerous health problems. Again a perception score was constructed using five items such as the eventual consequence of the disease being death, persistent poor health, giving birth to infected children, being rejected by society as well as the belief that infection with HIV leads to poverty. Correct mention or none mention was scored 1 else zero. The scale gave a mean score of 1.9 points. The median and modal scores were one point respectively on a five-point scale. Almost half (48.1\%) scored one sessions, agreed with the opinion typified in the statement of a female sex worker in Emene. According to her: "We are not doing this job because of the fun in it. It is because of hard times. We do it to survive and help our families. Even in some homes, the husbands arrange with the wife to do it and get money to cater for the family. Some use it to train others in school". Agreeing with this view, another participant from Emene, however opined that: "In some homes, the wives just sneak out to do it. They will tell their husbands that they are going to their place of trade (for the traders), or 
work and come to the brothel where they meet with men for money. It is all a question of survival, where the man of the home does not provide for the family or even for the wife"

Others stressed the fact that it is just for a while, and according to them this is the case with the students, who just use this to see themselves through school. They argued that when the pressure is over, and they get other income earning jobs that can adequately support them, they will quit commercial sex work and settle for a regular family life.

\section{Knowledge and practice on HIV/AIDS}

This section opened with inquiries on the common health problems the respondents were aware of. They were given opportunity to mention as many health problems as they could. From here, the visibility of HIV/ AIDS was gauged and subsequent issues, like the rating of the health problems and the respondents' reasons for the ratings explored. The most commonly mentioned health problem was malaria with 109 mentions (80.7\%). AIDS came a close second with $84(62.2 \%)$ mentions. Other health problems with high mentions were typhoid and gonorrhoea with 78 and 73 mentions, respectively. All the same $84.7 \%$ of the respondents considered HIV/AIDS a most deadly health problem. Very small proportions of the respondents considered malaria or any other health problems as most deadly.

Less than half $(47.2 \%)$ mentioned that the AIDS is linked to the infection by a virus called HIV. At least one in every four respondents $(25.2 \%)$ indicated that the virus is transmitted through eating with an infected person. A sizeable proportion (17.6\%) of the respondents also mentioned that one could get infected sleeping on the same bed with an infected person. Albeit, good proportions $(70 \%$, $85.5 \%$ and $73.3 \%$ ) of the respondents knew that one could get infected through the transfusion of infected blood, sexual intercourse with an infected person and sharing unsterilized sharp objects with an infected person respectively. On the signs and symptoms, $79.4 \%$ mentioned weight loss while $68.7 \%$ mentioned that an infected person is usually very sickly.

To actually gauge the knowledge of HIV / AIDS among the respondents, a cognitive scale was constructed using ten elements consisting knowledge on mode of transmission, signs/symptoms of AIDS as well as having ever seen one with the right symptoms mentioned. Each correct mention was scored 1 point while the wrong mention was scored 0 in each case.

The performance of the respondents on the cognitive scale revealed mean and median scores $( \pm S D)$ of $6 \pm 2.39$ points. Less than half $(42.0 \%)$ of the respondents scored $\leq 5$ points. Only $6.1 \%$ of the respondents scored the full 10 points available, while $18.3 \%, 13.0 \%, 8.4 \%, 9.9 \%$ scored 5, 6, 7 and 9 points respectively. On the other hand, one in every ten persons interviewed scored on three points. The performance scores of the respondents were checked against their educational background. The result of the inquiry revealed some level of correlation, though not statistically significant due to sample size, between the level of education of the respondents and their cognitive score (Pearson $R=0.133 ; P=0.13$ ). All the same the data revealed that the higher the level of education the higher the cognitive score on knowledge of HIV / AIDS among the respondents. Those with secondary or post secondary education scored ten points while none of those with primary education or no formal education scored ten points. Furthermore, while the median score among those with secondary or post secondary education was 7 and 6 points, respectively those with primary or no formal education had a median score of six points.

HIV / AIDS was classified as the most deadly disease by $89.2 \%$ because it has no cure. Smaller proportions of this group (AIDS as the most deadly), mentioned the fact that it kills fast $(8.1 \%)$, shameful $(3.0 \%)$ and very disturbing $(1.8 \%)$ as their reasons. On the other hand, respondents who considered malaria as the most deadly disease, mentioned the fact that it kills fast $(66.7 \%)$, and it is very disturbing $(33.3 \%)$ as their reasons. Hundred percent $(100 \%)$ of those who considered stomach ache as the most deadly thought so because it is very disturbing. The same goes for those who considered typhoid most deadly. However, for those mentioning gonorrhoea as the most deadly disease, being a shameful disease was one of the reasons mentioned by two-thirds $(66.7 \%)$ of this category of respondents.

The FGD sessions revealed people who were aware of the HIV / AIDS disease. In all the sessions, the participants mentioned HIV / AIDS among other diseases like malaria, typhoid, skin infection and gonorrhoea among others. For most of the participants agreed with a FSW from Agbani who said, "HIV/AIDS is the most dreadful disease because it has no cure... and because it kills..." A discussant in an FGD session with FSWs in Abakpa Nike, stressed that, I dread 
HIV/AIDS because the community and people run away from persons living with HIV". Among the modes of transmission they were unanimous on the fact that it is mostly transmitted through sexual intercourse. A typical expression in this direction is captured in a statement by one of the participants in the FGD session with FSWs in Emene. According to her, "it is passed from person to person during sex, especially as in the case of our male customers who do not like condom". In the FGD sessions, the participants mentioned signs and symptoms of HIV/AIDS just like those in the survey. These include weight loss, which ranked highest in mention, rashes, and weakness among others. According to the participants, the ultimate consequence of HIV / AIDS is death. But one of the participants stressed that, "the person will suffer for a long time until he or she dies". score were found among the respondents with higher levels of education. Further more it shows that while the median score was 2 point for those with secondary educational background or less, it is only 1 point for those with post secondary educational background. This suggests that educational background of the respondents could not adequately explain their perception of HIV / AIDS.

More than half $(58.8 \%)$ of the respondents thought it is not possible for them to get infected with HIV. Over eighty-seven percent $(87.9 \%)$ of this category of respondents indicated that they could not get infected because they are always protected. This was checked against the cognitive and perceptual scores as well as some demographic background of the respondents on HIV / AIDS (Table 2).

Table 2: Distribution of respondents by practice of protection against HIV/AIDS

\begin{tabular}{llll}
\hline Practice of protection & Response & Frequency & Percentages \\
\hline Possibility of getting infected & Possible & 54 & 41.2 \\
with HIV / AIDS & Impossible & 77 & 58.8 \\
Reason for the perceive & I trust myself & 6 & 7.6 \\
impossibility of HIV infection & & 1 & 1.3 \\
& I trust my partner & 67 & 87.9 \\
& I protect myself always & & 98.5 \\
Protection used by others & Use of condom & 129 & 8.4 \\
& Being faithful to one sex partner & 11 & 13.0 \\
& Abstaining from casual sex & 17 & 27.5 \\
& Use drugs & 36 & 23.7 \\
& Washing off immediately after sex & 31 & 9.2 \\
& Examining partners before sex & 12 & 19.8 \\
& Use herbs & 26 & $43.3 \%$ \\
Protection used by self & Other practices & 33 & 96.2 \\
& Use of condom & 126 & 14.5 \\
& Abstaining from casual sex & 19 & 9.9 \\
& Washing off immediately after sex & 13 & 11.5 \\
& Prayers & 32 & $24.5 \%$ \\
\hline
\end{tabular}

The influence of educational background of the respondents on their perception score on HIV/ AIDS was examined. Though not statistically significant, due to the smallness of the sample the value of the Pearson's $R(0.111, P=0.2)$ showed that there is a direct relationship between perception score and level of education of the respondents. It was revealed that while some of those with secondary educational background or more scored as much as five points, those with primary or non-formal educational backgrounds scored between 1 and 2 points only.

All the same, those with zero perceptual
The demographic backgrounds of the respondentsdidnotinfluencerespondents'belief of their susceptibility to HIV infection. On the other hand, the cognitive and perceptual scores of the respondents were statistically significant in explaining the perceived susceptibility of the respondents to HIV / AIDS. The higher the cognitive and perceptual scores the higher the perceived susceptibility of the respondents to infection with HIV/AIDS $(P=0.028)$. A higher proportion of those with formal education thought they could not be infected with HIV, while a higher proportion of those with no 
formal education think it is possible to get infected with HIV. Among the different marital groups no pattern could be discern. Those who have ever seen someone living with HIV/AIDS seemed to be more positive of the possible of getting infected.

Over ninety percent $(96.2 \%)$ of the respondents indicated that they protect themselves with condoms (Table 2). However, $11.5 \%$ and $9.9 \%$ of the respondents depend on prayers and washing off immediately after sexual intercourse with clients respectively. Others used herbs $(2.3 \%)$ or examine their sexual partner for any sexually transmitted diseases $(6.9 \%)$, be faithful to one partner $(3.1 \%)$, use charms $(2.3 \%)$ take hot drinks $(1.5 \%)$ and some few do nothing $(0.8 \%)$ to protect themselves. However, in mentioning what others do with respect to protection against HIV/AIDS, the largestproportions of therespondentsmentioned the use of condoms followed by drugs (27.5\%), washing off after sexual intercourse $(23.7 \%)$ and using herbs (19.8\%). Other mentioned practices included being faithful to one sex partner $(8.4 \%)$, take hot drinks after sex $(6.9 \%)$, use charms $(3.8 \%)$ and prayer (6.1).

\section{Peer education and skill acquisition programmes}

This section of the survey was devoted to exploring ways of improving knowledge, attitude and practice on HIV/AIDS as well as the economic existence of the sex workers. The feasibility of using peer education programme in achieving these objectives was the main focus of analysis here. Over seventy percent $(74.1 \%)$ of the respondents suggested the creation of awareness on the dangers of HIV / AIDS. Another $65.2 \%$, almost two-thirds of the respondents suggested that women should be given skills for self-reliance (see Table3). More than two-thirds $(70.4 \%)$ of the respondents indicated that government should be responsible for creating awareness on HIV / AIDS. More than half (52.6\%) of the respondents mentioned non-governmental organizations to play a role in creating awareness on HIV/AIDS. About a quarter $(26.7 \%)$ of the respondents mentioned indicated that colleagues who know could give awareness on HIV / AIDS. Almost one-third $(29.6 \%)$ of the respondents has never heard of the concept of peer education. However, among those who have heard of peer education, over ninety percent $(91.7 \%)$ would like to be trained to give information on HIV/AIDS to their colleagues.

Table 3: Distribution of respondents by attitude towards peer education programme

\begin{tabular}{lll}
\hline Response & Frequency & Percentages \\
\hline Suggestion for reducing HIV transmission among women & & \\
Create awareness on the dangers of HIV/AIDS & 100 & 74.1 \\
Create awareness on prevention of HIV/AIDS & 96 & 71.1 \\
Give women skills for self reliance & 88 & 65.2 \\
Give employment to women & 13 & 9.6 \\
Nothing & 7 & 5.2 \\
Who should create awareness for HIV/AIDS? & & \\
Government & 95 & 70.4 \\
NGOs & 71 & 52.6 \\
Community members & 31 & 23.0 \\
Community leaders & 57 & 42.2 \\
Peer/colleagues & 36 & 26.7 \\
Religious leaders & 5 & 3.7 \\
Ever heard of peer education? & & \\
Yes & 95 & 70.4 \\
No & 40 & 29.6 \\
Willingness to be trained as peer educator & & \\
Yes & 88 & 91.7 \\
No & 8 & 8.3 \\
\hline
\end{tabular}


Table 4: Distribution of respondents by opinions on income generating skills

\begin{tabular}{llll}
\hline Opinions & Response & Frequency & Percentages \\
\hline Is it good to train women on income & Yes & 134 & 99.3 \\
generating skills? & No & 1 & 0.7 \\
Reasons for the opinion on training & To make them self reliant & 99 & 73.3 \\
women on income skills & To keep them busy & 20 & 14.8 \\
& To earn a living & 84 & 62.2 \\
\multirow{2}{*}{ What would you like to be trained on? } & Dress making & 20 & 14.8 \\
& Hair dressing & 62 & 45.9 \\
& Confectioneries (baking) & 12 & 8.9 \\
& Cosmetology (pomade and & 9 & 6.7 \\
& soap making) & 17 & 12.6 \\
& Trading & 14 & 10.4 \\
& Processing of farm produce & 1 & 0.7 \\
& Nothing & & \\
Reasons for the choice of skills to learn & It sells around here & 59 & 43.7 \\
& Easy to learn & 62 & 45.9 \\
& Less money to start & 34 & 25.2 \\
\hline
\end{tabular}

Almost all the respondents (99.3\%) women thought it was good to train women on different income generating skills. For most of them $(73.3 \%)$ such skill training will make the women self-reliant. Further more, $62.2 \%$ of the respondents indicated that this would make the women earn a living for themselves. As individuals, a majority (45.9\%) of therespondents would like to be trained on hairdressing. Others would like to be trained on dress making $(14.8 \%)$, processing of farm produce $(12.6 \%)$ or on any income generating activities they could avail themselves (10.4\%).The respondents also gave reasons for their choice of skills. The commonest reason is the ease in learning the skill (45.9\%). Another $43.7 \%$ indicated that the skills they requested to be trained on sell within their environment (Table 4).

\section{Discussion}

The survey revealed varying socioeconomic backgrounds of the FSWs in Enugu. There were some educated and even currently in school. A good proportion of the sex workers were still of school age (16 years). A common feature of the FSWs in Enugu is their economic and social vulnerability. They are mostly unemployed and driven by economic challenges to take up the profession. This is similar with findings in other settings (Onwuliri \& Jolayemi, 2007). Okafor et al. (2003) demonstrated that in school adolescents especially the girls are often driven into sexuality with older and stronger wealthier men for money and protection. Similarly, Perkins et al. (2009) noted a link between economic situation of individuals and the risk of HIV infection in India. In this study, some of the respondents indicated that they exchange sex for money in order to meet their educational needs. Others, who were in marital unions, leave home every day to engage in the trade of sex work for the family sustenance.

Though some of the respondents showed good awareness of HIV / AIDS, a good number demonstrated outright ignorance of the disease and other reproductive health issues. Many mentioned that HIV / AIDS could be contracted through handshake, eating with infected person among other misconceptions. The knowledge index showed poor performance among the respondents. Similar findings had been noted in other studies both within and outside Nigeria (Araoye \& Fakeye, 1998; Okeibunor, 1999). According to Nwaorgu et al. (2008), juxtaposing the sexual activities of the vulnerable group with their acknowledged ignorance about protection against reproductive health hazards brings the imminent dangers to full glare. Thus, if we must avert the imminent threat of not only missing the millennium development goals but having an explosion of sexually transmitted hazards in our societies, effective and innovative approaches to addressing the reproductive health knowledge and practices of this segment of the population requires urgent attention. Though HIV/AIDS was recognized as the most dangerous in the communities, the level of ignorance on HIV/ 
AIDS and other reproductive health issues constitute a risk factor that calls for prioritized attention among the FSWs in Nigeria.

With respect to protection, most of the respondents rely on such as inspecting their clients for infection before sex. This is however very unusual in a society like Enugu with strong male dominance ideology. Women are not expected to discuss sex let alone inspect the genitals of a male client. However, where this is possible, it is on a very limited scale. Moreover, the sex workers lack scientific tools of inspection. This may therefore be very misleading and the women get involved in very risky sexual activity while believing that their clients are risk free. All the same, in a study of FSWs in a neighbouring Anambra State, Okeibunor (1999) observed similar practices among the FSWs. He thus concluded that while it is assumed that women are culturally constrained from discussing sex, this may not hold for the FSWs.

Other unorthodox methods such as washing after sex and use of herbs as well as taking hot drinks were equally employed especially among those who could not insist on the use of condom or inspection. Though a good number reported the use of condom, the others who fail to use condom remain instruments for the transmission of HIV in the society. This confirms the conclusions of the Millennium Development Goals Report for 2008 which was to the effect that AIDS continues to take a terrible toll in sub-Saharan Africa in spite of the recorded victories in other climes (UN, 2008).

The respondents suggested the creation of awareness on HIV/AIDS and its prevention among the commercial sex workers. Though they believed that this should be the responsibility of the government and NGOs, they were positively disposed to being trained as peer educators to train their peers. Since the respondents blamed their sex work on poverty they were also inclined to learning income generating skills that would help earn and be self reliant. The most popular skill among the sex workers were hair dress and dress making in that order. For them, these are not only easy to learn, they are in demand in the communities around them. A similar finding by Ogbogu et al. (2004) noted that absolute dependence of FSWs on the income derived from clients increased their risk of getting infection with HIV hence the need for income generating skills.

In conclusion, in terms of the characterization of the FSWs in Enugu, the study revealed that they are mostly within the productive age group, unemployed. Some of them are even married, but all claimed to have been driven into the trade of sex work for economic reasons. The level of knowledge of the dangers their activities constitute for them and the larger society however pose a serious threat to the realization of the MDG of halting and reversing the spread HIV / AIDS by 2015 (UN, 2008). In this case, the perceptual, attitudinal as well as cognitive factors which individually and jointly drive the FSWs into the practices about HIV/AIDS constitute the risk factors for the realization of HIV/AIDS free society. Another set of risk factor is the economic reality of the people which is often blamed for the involvement of the FSWs in the sex trade. According to Overs (2002) preventing transmission among persons with high rates of partner change due to economic demands is desirable and cost effective because it prevents more secondary cases per primary case averted than interventions directed at those who practise low risk sex. It follows that any investment to move this people out of sex work would move the society closer to the MDGs.

Following the findings of this study, it is recommended that steps be taken to improve on the level of knowledge of HIV / AIDS among the respondents. This should cut across sociodemographic lines. The results clearly points out important lessons for health education. This should target the perceptual factors, which tended to provide adequate explanation for the attitude of the respondents to HIV/AIDS. The sex workers could be trained as peer educators to give correct information and correct the misperceptions of the disease among the sex workers. The sex workers should be provided with income earning skills to improve their income earner ability and make them self reliant.

\section{Acknowledgements}

Support was received from the Society for Women and AIDS in Africa, Nigerian Branch and Mrs. Appolonia Obi in preparing this manuscript.

Received 5 May 2009

Revised 16 June 2009

Accepted 18 June 2009 


\section{References}

Araoye, M.O. \& Fakeye, O.O. (1998) Sexuality and contraception among Nigerian adolescents and youth. African Journal of Reproductive Health 2, 142-150.

Carrington, C. \& Betts,C. (2001) Riskand violence in different scenarios of commercial sex workers in Panama City. Research for Sex Work 1, 29-31.

Erah, P.O., Arienmughare, G. \& Okhamafe, A.O. (2003) Plasmodium falciparum malaria resistance to chloroquine in five communities in southern Nigeria. African Journal of Biotechnology 2, 384389.

EUROPAP/TAMPEP (1998) Hustling for Health. Developing Services for Sex Workers in Europe. Amsterdam: European Network for HIV/STD Prevention in Prostitution EUROPAP/TAMPEP.

FHI (2002) Behavioral Surveillance Survey. Family Health International, Arlington, Virginia.

Lamptey, P., Wigley, M. \& Carr, D. (2002) Facing the HIV/AIDS pandemic. Population Bulletin 57, 1-37.

Metzenrath, S. (1998) In touch with the needs of sex workers. Research for Sex Work 11, $1-3$.

NPC (2007) National Population Commission, Federal Republic of Nigeria Official Gazzette No. 24. Abuja, NPC. 94:B178198

Nwaorgu, O.C., Onyeneho, N.G., Onyegegbu, N., Okolo, M., Obadike, E., Ugochukwu, G., \&d Mbaekwe, C. (2008) Reproductive health knowledge and practices among junior secondary school grade one students in Enugu State: threat to achieving millennium development goals in Nigeria. East African Journal of Public Health 5, 126-131.

Okafor, C., Nwaorgu, O.C., Madu, E.N.
Okeibunor, J.C., Onyegegbu, N. \& Obong, N. (2003) Social context of adolescent's first sexual experience in Enugu State: evidence from focus group discussions. Scandinavian Journal of Development Alternatives and Area Studies 22 (3 \& 4), 104-120.

Okeibunor, J.C. (1999) Threat of AIDS and Condom use in a Nigerian Community: Implications for Fertility Regulation in Nigeria. Dakar: Union for African Population Studies, 36, 1-99.

Onwuliri, V.A., Kanki, P., Umeh, M.N. \& Awari, H. (2003) Educating sex workers in Nigeria. In: Nigeria's Contributions to Regional and Global Meetings on HIV/ AIDS/STIs (1986-2003). Lagos: Nigerian Institute of Medical Research.

Onwuliri, V.A. \& Jolayemi, O.M.J. (2007) Reaching vulnerable and high risk groups in Nigeria. http://www.apin. harvard.edu/Chapter14.pdf. Accessed 17June 2009.

Overs, C. (2002) Sex workers: part of the solution: an analysis of HIV prevention programming to prevent HIV transmission during commercial sex in developing countries, http://www. who.int/hiv/topics/vct/sw toolkit/ 115solution.pdf.

Perkins, J.M., Khan, K.T. \& Subrananian, S.V. (2009) Patterns and distribution of HIV among adult men and women in India. PloS One 4, e5648

UN (2006) The Millennium Development Goals Report. United Nations, New York.

UN (2008) The Millennium Development Goal Report. United Nations, New York.

USAID (2002) HIV/AIDS in Nigeria: A USAID Brief. Washington, DC.

WHR (2006) Updated with the World Health Statistics 2006. The World Health Report ttp://www.who.int/whosis/en/ 